\title{
"LAVA-LUZ" LUMINAIRE: A PEDAGOGICAL PROPOSAL FOR SCIENCE TEACHING
}

\author{
SILVA, Cleydivan Cunha ${ }^{1 *}$; DA SILVA, José Ailton Costa ${ }^{1}$; COSTA, Maurício Bezerra1; DE \\ CARVALHO, Rusbene Bruno Fonseca ${ }^{1}$ \\ ${ }^{1}$ Universidade Estadual do Maranhão - UEMA, Centro de Educação, Ciências Exatas e Naturais \\ Programa Darcy Ribeiro - PDR, Coelho Neto - MA, Brasil. \\ ${ }^{*}$ Autor correspondente \\ e-mail: kleydivan@gmail.com
}

Received 25 September 2014; received in revised form 11 December 2014; accepted 14 December 2014

\section{RESUMO}

Ensinar e aprender ciências são grandes desafios que requerem meios como recursos didáticos, audiovisuais, aulas expositivas, aulas de campo, entre outros. Para melhorar as aulas de ciências no ensino fundamental, é necessário que professores recebam melhores condições de trabalho e assim possam se empenhar em aulas dinâmicas que proporcionem facilitar a compreensão do aluno, levando-o a interagir como meio. Nesse contexto, nosso estudo tem como objetivo avaliar e observar, a participação, o estímulo e o conhecimento adquirido pelos alunos por meio de uma proposta pedagógica, podendo assim discutir como o ensino de ciências esta sendo desenvolvida em uma escola de rede municipal da cidade de Coelho Neto no Maranhão, bem como caracterizar o professor e a turma onde o estudo foi realizado. A pesquisa foi dividida em três etapas: levantamento de dados relacionados às características da escola, perfil dos professores e dos alunos, aula teórica expositiva e dialogada, e por fim, a atividade experimental. Os resultados revelam que a atividade experimental estimulou à assimilação de conteúdos, a criatividade, a participação, aprimorando a capacidade de observação e registro de informações, os fazendo propor hipóteses e questionamento sobre os fenômenos envolvidos no experimento.

Palavras chaves: Recurso didático, Ensino, Atividades experimentais.

\section{ABSTRACT}

Teaching and learning of sciences are huge challenges that require means such as didactic resources, audiovisual, expositive classes, field classes and so forth. To improve science classes in elementary school, it is necessary that teachers receive better working conditions and so can engage in dynamic classes that provide facilitate student understanding, leading him to interact as a means. In this context, our study aimed to evaluate and observe participation, stimulus and acquired knowledge by students through a new pedagogical proposal, enabling the discussion of how the teaching of sciences is being developed in a public municipal school from Coelho Neto, Maranhão, as well as characterize the teacher and the class where the study was conducted. Our study was divided in three steps: study of data regarding characteristics of the school, profile of students and teachers, then theoretical exposition and dialogue lectures, and finally the experimental activity. The results show that the experimental activity stimulated the understanding of content, creativity, participation, improving the capacity of observation and register of information, leading them to propose hypothesis and questions about the phenomena involved in the experiment.

Keywords: Didactic resources, Teaching, Experimental activities. 


\section{INTRODUÇÃO}

Uma das maiores dificuldades no ensino fundamental e médio é a falta de disciplina e educação dos alunos com relação a aulas ministradas, seja qual for à disciplina. Uma alternativa para motivar e a atrai-los para as aulas é a dinamização, e apesar do professor estar ciente dessa importância muitos ainda prende-se a aulas tradicionais, porém, insegurança, falta de apoio e infraestrutura das escolas são as principais dificuldades apresentadas aos professores na busca de uma melhor didática de ensino (ANDRADE; MASSABNI, 2011). .

Atualmente tem se pesquisado muito sobre novas metodologias que visem incentivar os alunos a buscar conhecimento (MARCOS; SILVA, 2010; CASTRO; COSTA, 2011; JOAQUIM, CAMACHO; 2014; COSTA; PINHEIRO, 2014), e a experimentação é uma forma de atrai-los para as aulas de ciências, articulando sempre teoria e prática (GIORDAN, 1999; CARVALHO, 2011; LIMA; SILVA, 2013; SILVA et al., 2014).

Porém, muitas escolas ainda não possuem infraestrutura que permita uso da experimentação no ensino de ciências, a grande maioria não possui laboratórios adequados e muito menos reagentes necessários para a elaboração desses experimentos (RAMOS; ROSA, 2008; CUNHA, 2012; ANDRADE; MASSABNI, 2011). No entanto, o ensino de ciências nos oferece um vasto campo de opções, podendo realizar experimentos de baixo custo e fácil acesso, empregando materiais presentes no cotidiano, sem prejudicar os objetivos e metas da aprendizagem (ASSUMPÇÃO et al., 2010).

Assim, ensinar e aprender ciências tornam-se grandes desafios que requerem estratégias correspondentes como recursos didáticos, audiovisuais, aulas expositivas, aulas de campo, feira de ciências, entre outros. Mediante isso, Golomambek (2004) ressalta que, a única forma de aprender ciências é fazendo-a, quer dizer que a sala de aula tanto de alunos de ensino fundamental como dos institutos de formação docente pode e deve transformar-se em um âmbito ativo de geração de conhecimento, afastado da mera repetição formalística e apoiado na experimentação e indagação constantes.
A ideia de experimentação está presente na história da humanidade. Desde os primeiros homens até os nossos dias, tudo começa de um pensamento, de uma necessidade. Depois vêm as tentativas, os erros e os acertos até acontecer o fato concreto. A ciência tem evoluído a tal ponto que traz inúmeras facilidades à vida diária, tendo em vista que, em quase todos os campos da atividade humana, existe a participação efetiva da comunidade científica (CRUZ, 2009).

As lâmpadas de lava são objetos que fazem parte da cultura pop dos anos de 1970 e são associadas a hippies e ao psicodelismo da época. Quando as lâmpadas de lava apareceram pela primeira vez, nos anos 70 , elas estavam presentes em dormitórios de colégios e em quartos de adolescentes ao redor do mundo (DOMINGOS, 2012).

Em alguns países, como Inglaterra e Estados Unidos, estas lâmpadas se tornaram um ícone da cultura popular, depois de todos esses anos, as pessoas ainda compram estas lâmpadas e os fabricantes oferecem centenas de opções de design. As lâmpadas de lava são dispositivo bastante simples, baseado em princípios científicos básicos, composto de poucos componentes. Elas possuem compostos que forma as "bolhas" flutuantes, clássico exemplo de compostos imersíveis em água e óleo (DOMINGOS, 2012).

Nesse contexto, o presente trabalho tem como objetivo avaliar e observar, a participação, o estímulo e o conhecimento adquirido pelos alunos por meio de uma proposta pedagógica, podendo assim discutir como o ensino de ciências esta sendo desenvolvida em uma escola de rede municipal da cidade de Coelho Neto no Maranhão, bem como caracterizar o professor e a turma onde o estudo foi realizado.

\section{METODOLOGIA}

A pesquisa foi desenvolvida em uma instituição de ensino da rede publica, localizada no centro da cidade de Coelho Neto, Maranhão. A realização desse trabalho foi dividida em três etapas. Inicialmente, na primeira etapa foi realizado um levantamento de dados relacionados às características da escola, perfil dos professores (Tabela 1) e alunos. O trabalho de coleta de dados contribui-o para a identificação dos participantes da pesquisa. 
Foi utilizado como instrumento de pesquisa um questionário abrangendo questões abertas. Nesse contexto, Chaer, Denis e Ribeiro (2011), afirmam que as perguntas abertas trazem a vantagem de não haver influência das respostas pré-estabelecidas pelo pesquisador, pois o informante escreverá aquilo que lhe vier à mente. Pois as perguntas fechadas não permitem que o sujeito/informantes expresse suas ideias ou opiniões porque as perguntas são pré-definidas e restringe a liberdade às respostas (BOAVENTURA, 2004).

Tabela 1. Questionário aplicado ao docente responsável pela disciplina de ciências da instituição.

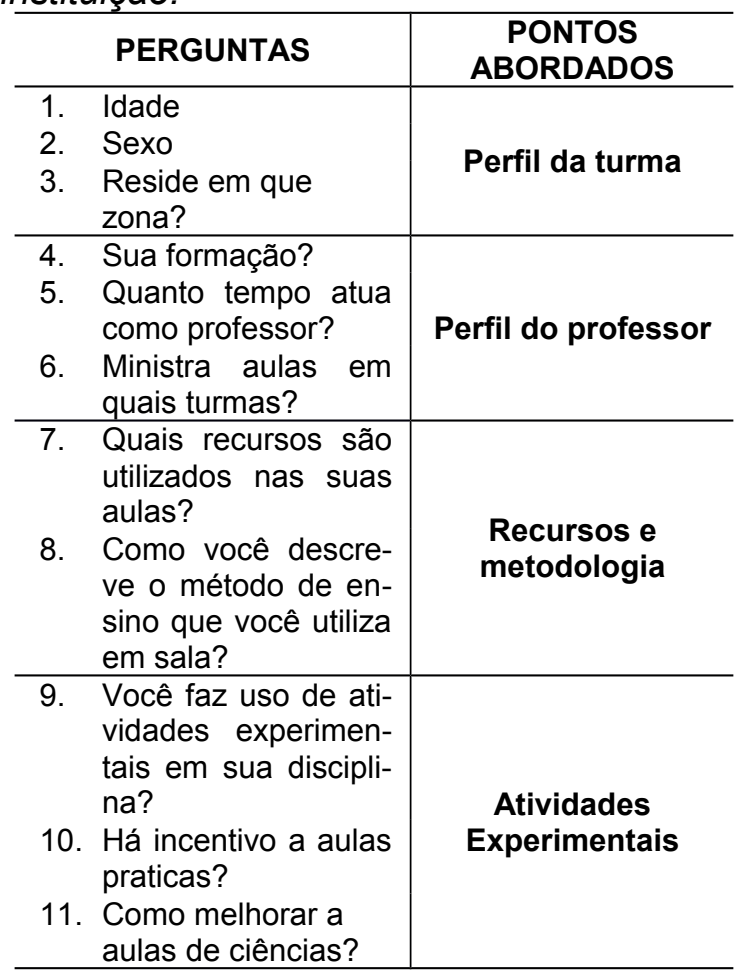

$\mathrm{Na}$ segunda etapa para melhor correlacionar a teoria ao experimento foi ministrada uma aula expositiva e dialogada abordando os conteúdos: densidade, misturas e reações químicas, apresentando exemplos de experimentos simples e pequenos vídeos, tornado a aula mais dinâmica e de melhor compreensão. Na realização da aula foi utilizado como recurso, o data show, ferramenta que ate então era pouca utilizada, é interessante que essa ferramenta acabou por despertar ainda mais a atenção e o interesse dos alunos.

$\mathrm{Na}$ terceira e ultima etapa, foi realizada a atividade experimental intitulada "Lâmpada lava- luz", envolvendo os conteúdos abordados anteriormente. $\mathrm{Na}$ realização do experimento foram utilizados materiais facilmente encontrados no dia a dia, tais como: garrafa de vidro transparente e vazia, óleo de cozinha, água, corante alimentar, comprimido efervescente.

É valido ressaltar que os alunos foram avaliados constantemente com relação à participação e colaboração com a aula experimental.

\section{RESULTADOS E DISCUSSÃO}

\section{Caracterizações da turma}

A pesquisa foi realizada na turma do nono ano do ensino fundamental no turno vespertino, em que a faixa etária dos alunos participantes da pesquisa variava entre quatorze e dezoito anos, onde foi constatado que dos vinte e dois alunos matriculados, apenas dezessete alunos frequentam regulamente as aulas, sendo onze são do sexo masculino e seis do sexo feminino e destes, $24 \%$ residem na zona rural e $76 \%$ na zona cidade.

Esses números podem representar a realidade e a estrutura do ensino na zona rural, pois esse não se encontra estruturado e organizado, e não atende totalmente a demanda de alunos na região. A ausência de uma boa infraestrutura das escolas rurais no município faz com que esses alunos acabem por migrar para escolas na cidade, consideradas de melhor qualidade, deixando assim em segundo plano a vida no campo e partindo em buscar de novas formas de conhecimentos (REIS NETO, 2005; CUNHA, 2012).

\section{Caracterização do professor}

O professor responsável pela turma ao qual a pesquisa foi desenvolvida é formado em licenciatura plena em matemática e física, possui especialização em estatísticas e atualmente esta cursando Direito, ele leciona a quinze anos, ministrando a disciplinas de ciências e matemática no sexto ao ano do ensino fundamental.

Com o objetivo de conhecer os recursos e a metodologia utilizada pelo professor, questionou-se sobre "Quais recursos são utilizados nas suas aulas?" e "Como você descreve o método de ensino que você utiliza em sala?". O professou apresentou as seguintes respostas, 
Meu método de ensino utilizado nas aulas é bem dinâmico e vários livros e revistas são utilizados para elaborar as aulas.

Em minhas aulas uso os seguintes recursos, giz, quadro acrílico, data show, retroprojetor, luneta e diversos materiais para experimentos científicos.

As respostas do professor descrevem bem a melhor maneira de conciliar aulas de ciências com atividades experimentais, demostrando utilizar-se de vários recursos, porém na prática isso não acontece.

Em conversas informais com os alunos da turma que foi desenvolvida a pesquisa, os mesmos alegaram nunca terem participado de aulas experimentais ou qualquer outra atividade prática que difere da aula tradicional. Diante desses comentários vimos à importância da nossa proposta pedagógica ser aplicada nessa escola.

Machado e Mol (2008) salientam que a experimentação exerce um papel importante no ensino-aprendizagem, nessa perspectiva, analisou-se a visão do professor sobre as atividades experimentais através das seguintes perguntas, "Você faz uso de atividades experimentais em sua disciplina?".

Sim, poucas, mas essas seguem os conteúdos e eles são avaliados com sua participação e empenho nas atividades experimentais.

"Há incentivo na realização de aulas praticas?" e "Como melhorar a aulas de ciências?".

Já que há pouco incentivo, para melhorar seria necessário o investimento em recursos para a construção de um laboratório na própria escola, com microscópios, vidrarias, entre outros, tornando assim, as aulas mais dinâmicas, colocando o aluno em contato com a natureza e os fenômenos que fazem parte dela.

O desenvolvimento de aulas experimentais é um grande desafio para os professores tendo em vista que na grande maioria das vezes não existe incentivo e muito menos estrutura para a realização de experimentos ou de qualquer outra atividade prática (ANDRADE; MASSABNI, 2011), porém existem diversas maneiras de diversificar as aulas, podendo conciliar materi- ais recicláveis com algumas atividades experimentais, utilizar aulas de campo, feiras de ciências e a criação de projetos que mobilize até mesmo professores de outras disciplinas.

Infelizmente, seja por falta de interesse, por pressa, seja pela correria do dia a dia ou ate mesmo por priorizar sua qualificação, muitos professores acabam por "ensinar" de qualquer forma e de qualquer jeito, prejudicando todo o processo de ensino-aprendizagem.

\section{Aplicações da proposta}

\subsection{Desenvolvendo a aula teórica}

No decorrer da aula foi observada as dificuldades dos discentes com os termos abordados, pois segundo eles, eram conteúdos bem complexos e que não chamava a atenção para os conteúdos expostos, dificultando assim a assimilação.

Segundo Gagliardi (1988), os conceitos de mistura, substância simples, substância composta, e elemento químico são considerados estruturantes em química. Sendo esses conteúdos abordados no inicio do ano letivo na disciplina de ciências, acredita-se que não seria encontrado tanta dificuldade. É importante destacar que todos esses conteúdos podem ser encontrados facilmente no livro didático entregue aos mesmos no inicio do ano.

\subsection{Realização do experimento}

Percebeu-se a necessidade da realização da atividade experimental após o termino da aula teórica, pois os alunos pouco questionaram e participaram timidamente. De acordo com Cruz (2009), para realizar aulas experimentais, precisamos planejar, antecipadamente, como a atividade será proposta, verificar todo o material que será utilizado, qual o melhor arranjo físico e qual a disposição dos alunos para tal experimento seja desenvolvido.

Dentro desse contexto, realizou-se a proposta pedagógica e na realização da atividade (Figura 1), foi colocado o óleo vegetal em uma garrafa de vidro transparente, até cerca de um quinto de sua altura. A partir dai misturou a água com o óleo até a formação de uma substância de duas fases, e em seguida o comprimido efervescente foi inserido na solução para que esse desse o efeito de uma luminária de lava. Embora os componentes da lâmpada de lava comercial se- 
jam patenteados, obtemos o mesmo efeito de forma bem mais simples.

No experimento, para a segurança dos alunos, optou-se por uma atividade demonstrativa, pois de acordo com Araújo e Abib (2003), os alunos apenas observam os fenômenos que são apresentados no experimento enquanto o professor é o responsável por realizar toda a atividade.
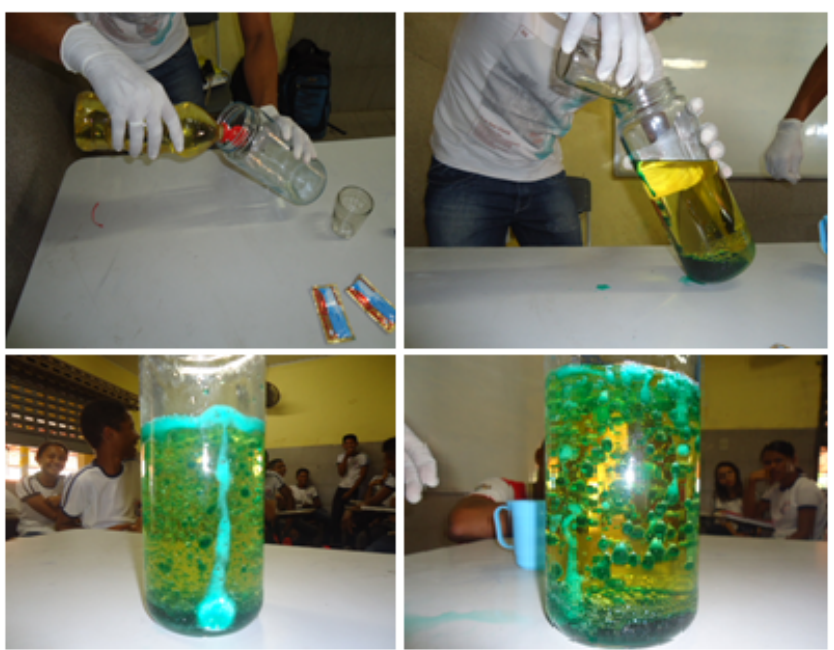

Figura 1. Realização do experimento em sala de aula.

Observou-se através da participação dos alunos que a atividade motivou e despertou a atenção, estimulou a criatividade, aprimorando a capacidade de observação e registro de informações, os fazendo propor hipóteses e questionamento sobre o fenômeno envolvido no experimento. Dentre esses questionamentos, podemos citar como exemplo,

Por que o corante verde e o óleo não se misturam?

Por que o óleo ficou na parte de cima e não na de baixo?

Por que o comprimido efervescente não faz bolinha em contato com o óleo?

Por meio das discussões criadas a partir dos questionamentos levantados pelos os alunos foi possível verificar que é necessário utilizar novas metodologias, objetivando melhorar a assimilação dos conteúdos expostos na aula teórica, e nossa perspectiva, nossa proposta pedagógica da atividade experimental luminária "lava-luz" mostrou ser um ótimo exemplo para trabalhar conteúdos relacionados mistura, substância simples, substância composta, reações química, entre outros.

\section{CONCLUSÃO}

A atividade experimental realizada mostrou ser uma alternativa simples e viável para o ensino de ciências, podendo ser realizada mesmo em instituições que não apresentem infraestrutura adequada para realização de experimentos. Tal experiência vivenciada pelos alunos possibilitou uma reflexão critica do conhecimento cientifico possibilitando interagir, e levantar questões e ideais.

É valido ressaltar que o professor tem papel fundamental no desenvolvimento dessas atividades, devendo sempre estimular os alunos a explorarem suas ideias e opiniões para explicar fenômenos apresentados nas atividades. Nesse contexto, surgi a necessidade da criação de laboratórios de ensino nas escolas da rede pública, seja ele fixo ou móvel, para que mais atividades sejam realizadas, transformando o aluno em sujeito ativo no processo de ensino-aprendizagem.

\section{AGRADECIMENTOS}

Ao Programa Darcy Ribeiro da Universidade Estadual do Maranhão (UEMA).

\section{REFERÊNCIAS:}

1. Agustinho, E. C.; Geglio, P. C. Resumo do XII Encontro de Iniciação à Docência UFPB-PRG, João Pessoa, Paraíba, Brasil. 2010.

2. Andrade, M. L.; Massabni, V. G. Ciênc. educ. , 2011, 17(4), 835.

3. Araújo, M. S. T; Abib, M. L. S. Rev. Bras. Ens. Fis. 2003, 25(2), 176.

4. Assumpcao, M. H. M. T.; Freitas, K. H. G.; Souza, F. S.; Fatibello-Filho, O. Eclet. Quím. 2010, 35(4), 133.

5. Boaventura, E. M. Metodologia da Pesquisa: monografia, dissertação e tese. São Paulo: Atlas, 2004.

6. Carvalho, R. B. F. Trabalho de Conclusão de Curso, Universidade Federal do Piauí, Brasil, 2011.

7. Castro, B. J.; Costa, P. C. F. Rev. electrón. investig. educ. cienc. 2011, 6(2) 25.

8. Chaer, G.; Diniz, R. R. P.; Ribeiro, E. A. Evidência. 2011, 7(7), 251.

9. Costa, J. M.; Pinheiro, N. A. M. Rev. 
SBEM RS. 2014, 1(15), 6.

10. Cruz, J. B. Laboratórios. Brasília: Universidade de Brasília, 2009.

11. Cunha, R. ComCiência. 2012, 135, 0.

12. Domingos, G. 2012. Disponível em: <http://georgequimica.blogspot.com.br>. Acesso em 24 de abril de 2014.

13. Fracalanza, H; Amaral, I. A.; Gouveia, M. S. F. O ensino de ciências no primeiro grau. São Paulo: Atual, 1986.

14. Gagliardi, R. Como utilizar la historia de las ciencias em la enseñanza de las ciências. Rev. electrón. enseñ. cienc. 1988, 6(3), 291-296.

15. Giordan, M. Quím. Nova Esc., 1999, 10, 43.

16. Golombek, D. A. Aprender e ensinar Ciências: do laboratório à sala de aula e vice-versa. $2^{a}$ ed. Sangari do Brasil: Fundação Santillana, 2009.

17. Guimarães, S. S. M.; Favetta, L. R. A. EccoS - Rev. Cient. 2013, 31, 181.

18. Joaquim, F, L.; Camacho, A. C. L. F.
JNUOL. 2014, 8(4), 1081.

19. Krasilchik, M. O professor e o currículo de Ciências. São Paulo: EPU/EDUSP, 1987.

20. Lima, D. S.; Silva, C. C. Itiinerarius Reflections. 2013, 2(15), 1.

21. Maia, R. Programa Completo de Matérias. São Paulo: DCL, 2004.

22. Machado, P. F. L; Mól, G. S. Quím. Nova Esc. 2007, 27, 57.

23. Marques, F. F.; Silva, K. C. Rev. Igapó. 2010, 1(1), 1.

24. Ramos, L. B. C.; Rosa, P. R. S. Experiencia em ensino de ciências. 2008, 13(3), 299.

25. Reis Neto, A. Dissertação de mestrado, Universidade Federal do Ceará, Brasil, 2005.

26. Silva, G. S.; Braibante, M E. F.; Braibante, H. T. S.; Pazinato, M. S.; Trevisan, M. C. Ciênc. educ. 2014, 20(2), 481. 